\title{
CHRONIC IDIOPATHIC AGRANULOCYTOSIS Report of a Fatal Case Treated with Corticotrophin (ACTH)
}

By I. M. Librach, M.B., B.Ch., D.P.H., D.C.H. Medical Officer-in-Charge, Ilford Isolation Hospital

In 1922 Schultz described the clinical picture of a fatal necrotizing throat infection usually occurring in elderly females. Since then many. cases of agranulocytosis (as it was named) have been described, the majority due to secondary marrow intoxication with chemical agents containing a benzene grouping. The primary or idiopathic variety still remains a mysterious malady, occurring at all ages, especially in females, and about whose causation little is understood.

Since 1934 only 30 cases or so have been recorded in the United Kingdom. There has been no survey of the whole subject in this country for the past ro years, apart from the contribution of Adams and Witts in 1949, when five cases were described and discussed.

Treatment remains problematical. Many forms have been tried and are well known. They include splenectomy, irradiation, nucleotides, glutathione, liver extract, the various components of the $B$ complex of vitamins, especially pyrodoxine, folic acid and cyanocobalamin, transfusion of whole blood or its constituents, especially leucocyte cream, bone marrow and leukaemic extracts. The greatest advance so far has been the use of antibiotics and in particular penicillin, which helps to prevent those infections previously proving fatal.

Due to the paucity of suitable cases, reports of the effect of ACTH have been few in number, especially in regard to the idiopathic variety. Its use in the following case, which was observed over three years, is therefore described.

\section{Case Report}

K.M.C., a housewife aged 53 -years, was first admitted on 30.9 .52 as a case of pneumonia. She had complained of pain in the right side of the chest for two days.

Shortly after the death of her son in 1943 she developed pains in the hands, knees, ankles and feet, which were ascribed to rheumatoid arthritis and treated as such. She had taken various proprietary brands of aspirin up to nine tablets daily to relieve these pains without much success.
In $195^{1}$ she was treated for septic feet.

\section{On Examination}

T. 102 ${ }^{\circ}$. P. 124. Resp. 42. Depressed and ill. Dry, furred tongue. Edentulous. Tachypnoea. No rash, glands, or ulceration. Both lung fields showed multiple crepitations, especially in right mid zone. B.P. 135/85. Heart sounds normal. Hands soft, pale and smooth with little evidence of articular thickening. Some saphenous varices present.

\section{Investigations}

$\mathrm{X}$-ray chest 2.10.52. Patchy consolidation right lung field. Sputum: no predominant organism isolated. No acid-fast bacilli present.

On admission: white cells 1,600 . No granulo cytes, only a few premature cells.

Blood group ' $\mathrm{O}$ ' $\mathrm{Rh}$ positive.

Sternal marrow film I 1.10.52: no granulocytes. Only a few myelocytes. 42 per cent. lymphs. Normoblasts + .

\section{Treatment}

Benzyl penicillin, $1,000,000$ units intramuscularly six-hourly for 38 mega units. Chlortetracycline, $500 \mathrm{mg}$. six-hourly for five days. Sodium pentose nucleotide, $5 \mathrm{ml}$. twice daily for four days I.M. Aq. gentian violet, I per cent. to mouth One pint compatible and cross-matched blood. Heparin, 10,000 units I.M. six-hourly for 2,800,000 units. Pyrodoxine, roo mg. I.V. for four days. Ascorbic acid, 1,000 mg. daily.

\section{Progress}

Initial improvement occurred, apart from a herpetic eruption of the lip. The chest cleared by 8.10.52, but numerous small shallow ulcers of tonsillar fossae and palate developed. She was frail and weak. By 27:10.52 the ulceration was worse. On 3.11 .52 a blood transfusion of one pint whole blood was given. Four days later pitting oedema of left leg developed with tenderness in Scarpa's triangle. By II.11.52 both the leg and 


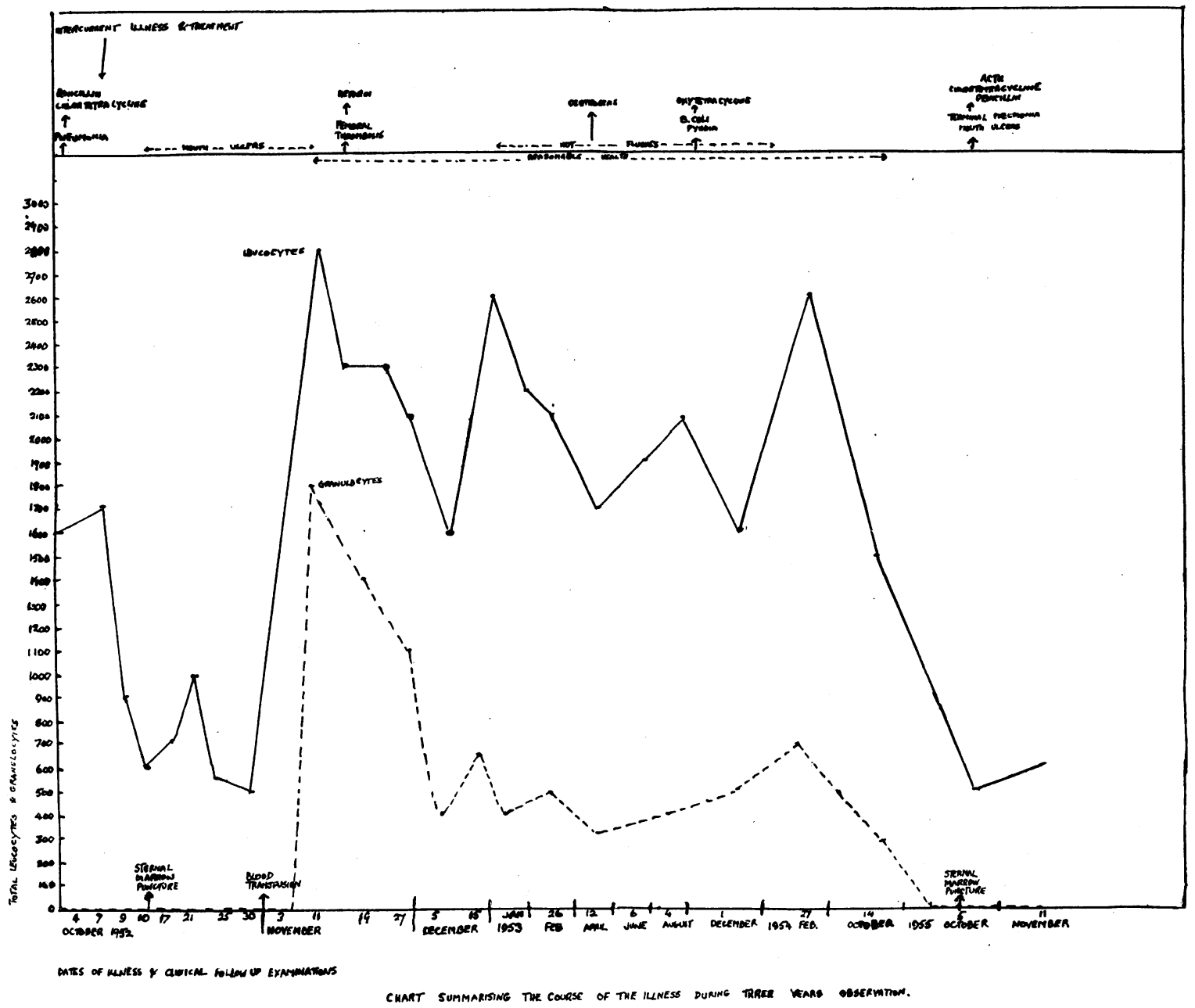

mouth had improved. Progress, if any, was still very slow, but by 10.12.52 she had recovered sufficiently well to go home. The leg was still swollen and an elastic stocking was ordered.

\section{Follow-up}

I.I.53 to 6.6.53. Has felt well, apart from occasional headaches and hot flushes. No ulceration present. B.P. I 50/90: Weight i I st. 5 lb. Oral oestrogens prescribed.

29.7.53. Readmitted to hospital with right-sided abdominal pain for three days. C.S.U.: pus cells and $B$. coli. W.C.C. 2,800. Polys 12 per cent. Discharged well on 28.8.53 after treatment with citrates and oxytetracycline.

28.1I.53 to 27.2.54. Vague aches, headaches, hot flushes, but looks and feels well. Weight 13 st. Meibomian cyst of eyelid present. W.C.C. 1,400 . Polys Io per cent.

24.ro.55. Defaulted from out-patients' during the first half of 1955 and then readmitted to hospital with headache, coryza and increasing cough for seven days. Treated at home with sulphatriad. T. 102. P. 124. Resp. 24. Flushed. Right nostril ulcerated. Bilateral basal crepitations. Increasing pallor, lethargy, weakness, necrotic ulceration of the ongue and dysphagia occurred.

She died 17 days after admission and three years, 2/12 after originally seen. No post-mortem performed, but cause ascribed to bronchopneumonia despite negative $\mathrm{X}$-ray findings.

\section{Investigations}

25.10.55. Chest X-ray clear! C.S.U. normal. W.C.C. $500 / \mathrm{cu} . \mathrm{mm}$. No granulocytes.

4. I I.55. W.C.C. $600 / \mathrm{cu} . \mathrm{mm}$. No granulocytes. 25.10.55. Hb 99 per cent. R.B.C. 4,800,000/cu. $\mathrm{mm}$.

4.I I.55. Hb 75 per cent. R.B.C. 3,880,000/cu. $\mathrm{mm}$. Group ' $\mathrm{O}$ ' $\mathrm{Rh}$ positive. 
7.11.55. Sternal marrow puncture; the marrow is erythropoetic and shows red cell precursors. No platelet deficiency. The predominant cell is a small lymphocyte: cells of the granulocyte series almost completely absent, a rare promelocyte and eosinophil are seen.

The picture suggests an actual aplasia of granulocytic system. The lymphocytes are small and mature. There is no accordance with a leukaemic state.

\section{Treatment}

Penicillin : chlortetracycline.

8.I I.55. Soluble corticotrophin, $25 \mathrm{mg}$. sixhourly I.M. for three days before death.

\section{Discussion}

There seems little doubt that the case described conforms to the clinical and pathological picture of idiopathic aplastic agranulocytosis. It would appear that the first symptoms (fleeting pains) commenced some time after 1943, which would suggest that the duration of the illness was approximately 12 years. The fact that aspirin was used after the onset of the joint pains makes this unlikely as the causal factor. It is of interest that the patient's illness started after a severe mental shock, namely, the death of her son. Whether such shock acts as a trigger mechanism, in predisposed adults at any rate, is conjectural. Although most cases occur in adults, the condition does occur in early infancy, e.g. two years (Bruck, 1947; Moncrieff, I95I). However, at this early age it may well be that the infection which usually acts as a precipitating factor could be the cause rather than the result of the granulopenia, due to the immature condition of the infantile bone marrow.

A further similar personal case occurring in an adult female aged 57 years may be interposed here. She was admitted on $\mathbf{2 5} \cdot 5 \cdot 5^{2}$ suffering from staphylococcal septicaemia. An initial white cell count showed 330 white cells with no granulocytes. Eleven days later the count had risen abruptly and permanently to $2 \mathrm{I}, 200$, of which 78 per cent. were granulocytes, 27 per cent. being immature. Treatment included penicillin, chlortetracycline and pentnucleotide.

Witts classified the disease amongst the aplastic anaemias, but as their cause is equally obscure this is of little help in treatment. Most of the recorded cases occur in females, but whether this means that the female sex hormone in whole or part acts as a marrow depressant under certain circumstances is disputed.

Most of the cases are fatal nowadays as a result of the disease itself rather than from secondary infections, which are controlled by antibiotics. Despite this, it seems that sufferers can survive for many years; thus Spaet and Damshek record a $\frac{0}{0}$ case in a woman of 63 years who survived for 25 years. The present case as mentioned probabiy lived for 12 years.

In a disease of such varying course and long $\stackrel{\varrho}{c}$ duration it is natural that attempts should be made $\stackrel{\vec{\Rightarrow}}{\vec{*}}$ to classify it on a ' chronological' basis. Thus $\stackrel{\vec{\rho}}{\overrightarrow{9}}$ acute fulminating, chronic insidious, relapsing and $\bar{c}$ cyclical varieties have been described. I myself (1946) postulated a critical level of leucopenia $\frac{\bar{\omega}}{7}$ below which symptoms might occur. However, a $\stackrel{\mathbb{Q}}{\Omega}$ study of recorded cases would seem to point to chance rather than any specific pathological factor as the cause of the variations.

The course of the illness bears some resemblance $\overrightarrow{\vec{\omega}}$ to the reticuloses, especially leukemia and Hodg- ${ }^{\circ}$ kin's disease, both of which are characterized by relapses and remissions. Whether some similar 3 . malignant cellular process is the cause is debatable.

It is difficult, therefore, to prognosticate in a $\omega$ given case. A month after the original admission of the present case her condition appeared as grave $\overrightarrow{0}$ as the day on which she died, yet this occurred $\not$ three years later! The results of treatment, too, are difficult to appraise. Credit for cure or remission $\rightarrow$ is usually given to the last treatment employed.

Nowadays, when in doubt, cortisone or corticotrophin is widely employed after all else has failed. $\stackrel{\infty}{\rightarrow}$ Cortisone stimulates haemopoiesis, so that th\& $\overrightarrow{0}$ somewhat rationalizes its use in haematolog of although its mechanism is unknown. Corticer. trophin was used as a last resort in this case three years after the original diagnosis. The soluble as distinct from the gel variety was employed because it was considered that absorption would be quicker. Intermittent intramuscular dosage $(25 \mathrm{mg}$. six- $\stackrel{\varrho}{\Rightarrow}$ hourly) was felt to be as effective as the continuous intravenous method.

Although it was intended to continue it, if effective, for an indefinite period, perhaps on a maintenance dose basis, three days later the patient's $\frac{0}{3}$ condition was no better and she died before any real assessment of its value could be made. 3 . Whether this result was due to 'too little being given too late' is questionable, because of the unpredictable nature of the malady. Some spon- 0 taneous recovery of her marrow function had occurred by 27.12 .54 , when the white cell count $\frac{D}{2}$ rose to 2,600 , Polys 20 per cent. It is conceivable that if corticotrophin had been employed at this $N$ time any recovery may have been ascribed to its $N$ use. It would seem, however, that if the marrow is N or becomes aplastic, as in the present instance, then ${ }_{\sigma}^{\omega}$ no form of stimulation would be of any avail. Whether cortisone itself would have been better $\frac{O}{D}$ than corticotrophin is also conjectural. It is possible that the adrenal glands were so depressed ${ }_{T}^{+}$ by the long-continued effects of the illness that 
they were unable to be stimulated. What the effect of agranulocytosis is on these glands, I do not know. However, it might seem in retrospect more rational to use cortisone rather than corticotrophin in this and similar states.

Martennson and Vikbladh (1954) discussed the serum protein findings in a woman of 49 years who had thyrotoxicosis in 1948 followed by granulopenia for six years. Studies showed a pathological protein fraction constituting 30 per cent. of total proteins which immigrated at the same rate as gamma globulin and which agglutinated normal leucocytes, especially neutrophils. They therefore postulated that neutropenia is the result of auto-immunization, causing intravascular destruction of leucocytes. Two other cases, however, did not show the same phenomenon. Whether the thyrotoxicosis, too, was a factor also remains disputable. If an allergic basis were postulated, the use of cortisone and ACTH might be rationalized still further. However, one swallow does not make a summer and no firm conclusions can be drawn from a single case. Its use, therefore, remains sub judice.

\section{Summary}

I am indebted to Dr. J. Spencer, consulting pathologist to this hospital, for the marrow films and to Mr. L. Whittaker, A.I.M.L.T., for the laboratory investigations. I must also thank the Librarian of the Royal Society of Medicine for help with the references and Dr. R. W. Tannahill (consultant to the N.E. Met. R.H.B.) for his encouragement.

\section{BIBLIOGRAPHY}

ADAMS, E. B., and WITTS, L. J. (1949), Quart. F. Med., 18, 173. BRUCK, E. (1947), Amer. F. Dis. Child, 73, 186.

LIBRACH, I. M., and CRONIN, R. G. (1946), Brit. med. F., 2, 897. MARTENNSON, J., and VIKBLADH, I. (1954), Blood, 6, 632. MONCRIEFF, A. (1951), Arch. Dis. Child, 26, 438.

SPAET, T. H., and DAMESHEK, W. (1952), Amer. F. Med., 1335. SCHULTZ, W. (1922), Deutsch. Med. Wchschr., 48, 1495.

WITTS, L. J. (1936), Proc. R. Soc. Med., 29, 67 I.

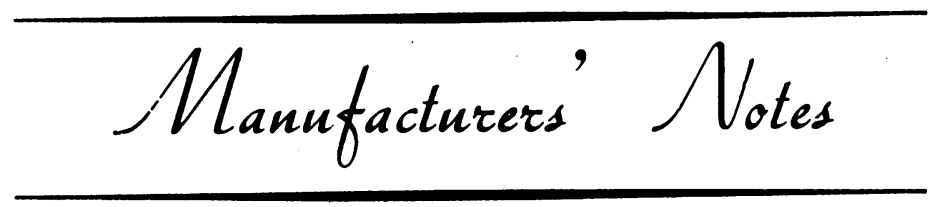

\section{STREPTODUOCIN VIULES}

Boots Pure Drug Company Limited announce the availability of Streptoduocin Viules (Stabilised injection of Streptomycin and Dihydrostreptomycin).

Streptoduocin Viules contain $2 \mathrm{ml}$. of stabilised solution equivalent to $0.5 \mathrm{~g}$. of Streptomycin and $0.5 \mathrm{~g}$. of Dihydrostreptomycin ds sulphates.

Streptoduocin is the name approved by the B.P. Commission for an injection containing equal parts of Streptomycin and Dihydrostreptomycin.

Face Price: Packs of $6 \times 2 \mathrm{ml}$. .. I $5 \mathrm{~s}$. Packs of $100 \times 2 \mathrm{ml}$... 244s.

\section{'HIBITANE' ANTISEPTIC LOZENGES}

Imperial Chemical (Pharmaceuticals) Limited announce that they are now issuing 'Hibitane' Antiseptic Lozenges. These Lozenges are intended for use in the prevention and treatment of infections of the mouth and throat and for the relief of sore throat and laryngitis. Each lozenge contains $5 \mathrm{mg}$. of the new antiseptic, 'Hibitane' chlorhexidine dihydrochloride and $2 \mathrm{mg}$. of Benzocaine B.P. incorporated in a pleasantly flavoured base. 'Hibitane' Lozenges are issued in tubes of 12 lozenges.

\section{' PREMARIN'}

Imperial Chemical (Pharmaceuticals) Ltd. annouce the introduction of 'Premarin' on to their medical range of products. 'Premarin' is a preparation of orally active, water-soluble oestrogens derived from pregnant mares' urine.

This preparation of oestrogens is unique in that it is several times more active when taken by mouth than other oestrogens obtained from the same source. It is well tolerated, rapidly absorbed and is comparatively free from side effects; even on prolonged and high oral dosage. The main indications are:-

Functional uterine bleeding.

Hypogenitalism and functional amenorrhoea.

Symptoms of the menopause.

Senile vaginitis, kraurosis vulvae and pruritus vulvae.

Inhibition of lactation.

Prostatic carcinoma.

'Premarin' is being distributed in the United Kingdom by arrangement with Ayerst McKenna and Harrison Ltd., Montreal, Canada. The drug is presented in tablets of $0.625 \mathrm{mg}$. and $1.25 \mathrm{mg}$. (total conjugated oestrogens (equine)) and may be prescribed under the National Health Service. 